\title{
Fluid and melt inclusion evidence for immiscibility at Somma Vesuvius Volcano (Italy)
}

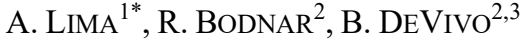 \\ ${ }^{1}$ University of Naples "Federico II", Naples, Italy \\ (*correspondence: anlima@unina.it) \\ ${ }^{2}$ Virginia Tech, Blacksburg, VA 24061 (rib@,vt.edu) \\ ${ }^{3}$ Pegaso On Line University, Naples, Italy
}

Preliminary FI and MI results on Somma Vesuvius skarns have been used to develop a model for the sub-surface environment as shown below. Skarns are representative of the shallow intrusive system where transition from a magmadominated to a fluid-dominated system takes place [1]. During the late stages of magma evolution, $\mathrm{H}_{2} \mathrm{O}$ is likely to react with the chloride, fluoride, borate and carbonate species and the chemical effects of high-temperature hydrolysis may be greatly enhanced by phase separation and multiple immiscible fluid phases can form [2]. As such, a crystal that forms in the LLI zone shown below, where $\mathrm{T}<1000{ }^{\circ} \mathrm{C}$, can trap different types of FI and MI.

FI and MI in wollastonite, apatite, calcite show evidence of liquid-liquid immiscibility (LLI) during magmatic differentiation. LLI likely leads to the formation of local magma pockets that evolve independently and to different degrees. Petrological signatures for the different melts might be mis-interpreted to represent mixing and/or mingling.

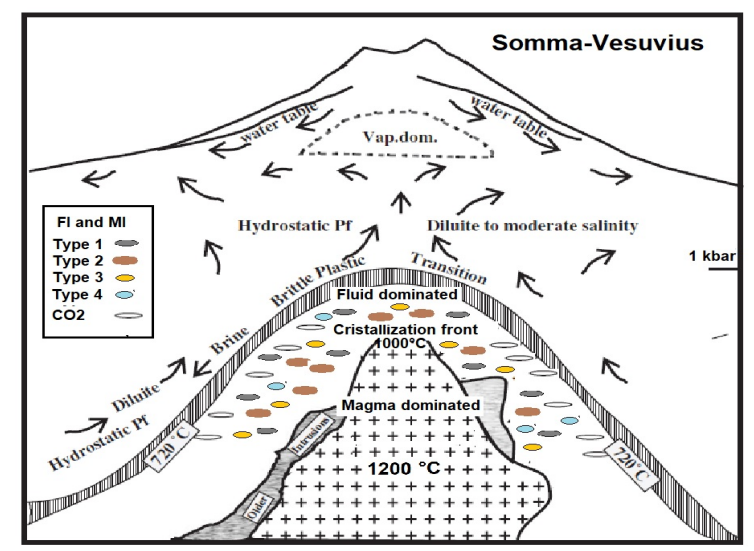

[1] Lima et al. (2007) Chemical Geology 237: 401-417 [2] Veksler \& Charlier (2015) In: B. Charlier (eds), Layerd Intrusions, Springer Geology 